\title{
Consciência morfológica em crianças do pré-escolar dos meios rural e urbano:
}

\author{
estudo comparativo
}

\section{Morphological awareness in preschool children from rural and urban areas: a \\ comparative study}

\author{
Florbela Henriques*, Inês Gomes** \\ *Santa Casa da Misericórdia da Murtosa, Portugal, **Universidade Fernando Pessoa, Porto, Portugal
}

\begin{abstract}
Resumo
Pretende-se com este estudo analisar o papel do meio no desenvolvimento da capacidade de refletir, analisar e manipular intencionalmente a estrutura morfológica das palavras. Foram observadas 60 crianças portuguesas (30 do meio urbano + 30 do meio rural), de 4 e 5 anos de idade, em tarefas de consciência morfológica. O desempenho das crianças de ambos os grupos foi globalmente baixo. Ainda assim, observou-se uma vantagem significativa do meio urbano em tarefas de identificação e de categorização de morfemas radicais e derivacionais. Tais resultados alertam para a importância de se implementar programas de treino de consciência morfológica em idade pré-escolar.

Palavras chave: consciência morfológica, idade préescolar, meios rural e urbano
\end{abstract}

\begin{abstract}
This study aims to compare the level of development of the ability to intentionally reflect on, analyze and manipulate the morphological structure of words in rural and urban preschool children. Sixty Portuguese children (30 from urban areas +30 from rural areas), aged 4 and 5 years, were assessed with morphological awareness tasks. The performance of children from both groups was overall low. Nevertheless, a significant advantage of the urban group was observed in tasks regarding the identification and categorization of radical and derivational morphemes. These results highlight the importance of implementing morphological awareness training programs at pre-school age.

Keywords: morphological awareness, preschool children, rural and urban zones
\end{abstract}

A literatura tem evidenciado o papel determinante das habilidades metalinguísticas na aprendizagem da leitura e da escrita, com especial enfoque na consciência fonológica. No entanto, nas últimas décadas, a importância da consciência morfológica na apropriação do código escrito tem merecido uma especial atenção por parte dos investigadores (Apel, 2014). Esta importância encontra fundamento, desde logo, na própria natureza morfofonémica das ortografias alfabéticas, em que muitas das irregularidades do ponto de vista fonémico são regulares do ponto de vista morfológico (Arnbak \&
Elbro, 2000). Por outro lado, sendo os morfemas unidades com sentido, é possível compreender muitas palavras novas a partir da análise dos seus morfemas constituintes. Também de um ponto de vista cognitivo, a existência de erros ortográficos de natureza morfológica permite aventar a possibilidade de o léxico mental se encontrar morfologicamente organizado (Casalis \& Louis-Alexandre, 2000). No seu conjunto, estes argumentos deixam antever uma estreita relação entre a consciência morfológica e o ato de ler, relação esta que se assume complexa já que, contrariamente aos fonemas, os morfemas são dotados de propriedades semânticas, sintáticas, fonológicas e relacionais (ibidem).

Apesar do crescente reconhecimento da importância desta habilidade para a aprendizagem da linguagem escrita, subsiste, ainda, alguma dificuldade na definição deste construto dada a sua complexidade e abrangência (Apel, 2014). Em termos gerais, a consciência morfológica remete para a capacidade de refletir, de analisar e de manipular intencionalmente a estrutura morfológica das palavras (Kirby et al., 2012). Ao invés de operar sobre os fonemas ou sequências de fonemas sem significado, como o faz a consciência fonológica, a consciência morfológica opera sobre os morfemas e as relações que estes estabelecem entre si.

O morfema é definido como a unidade linguística mais pequena portadora de significado próprio, correspondendo, deste modo, a uma unidade fonológica que encerra informação semântica (Lieber, 2016; Villalva, 2009). Esta unidade mínima da fala com significado pode ser de três tipos: o radical (morfemabase), os afixos e as desinências. O radical, também designado de raiz, corresponde ao "núcleo mínimo de uma construção morfológica” (ibidem, p. 311), podendo ocorrer isoladamente na língua. Uma vez que ele próprio pode corresponder a uma palavra é designado de morfema livre. Já os afixos são unidades apenas com significado gramatical, não podendo ocorrer isoladamente - por esta razão são considerados morfemas presos. Os afixos são morfemas derivacionais que se encontram na base da formação de novas palavras. Consoante a sua posição na palavra, os afixos podem ser prefixos (se estiverem antes do radical) ou sufixos (se 
estiverem depois do radical). Em geral, os prefixos mudam o significado do radical mas não alteram a sua classe gramatical; já os sufixos, para além de mudarem o significado, alteram, na sua maioria, a classe gramatical do radical (Villalva, 2009). Tal como os afixos, também as desinências (ou morfemas de flexão) constituem morfemas presos, sem autonomia lexical. O seu significado é gramatical, acrescentando ao radical informação relativa ao número, género, tempo verbal e grau, adquirindo, deste modo, um caráter morfossintático e estabilidade semântica.

No que toca à natureza da significação, estes três tipos de morfemas são classificados como lexicais ou gramaticais. Os morfemas lexicais, onde se inclui o radical, apresentam significação externa enquanto os morfemas gramaticais (afixos e desinências) têm apenas significação interna (ibidem). Os morfemas podem ser, assim, palavras inteiras (e.g., o substantivo casa) ou uma parte da palavra, portadora de significado (e.g., o " $s$ " na palavra casas, significando mais de um). Decorre daqui que as palavras podem ser consideradas simples, quando possuem um só morfema, ou complexas, quando são compostas por mais do que um morfema.

Esta complexidade morfológica não se limita apenas ao número de morfemas de uma dada palavra, podendo, ainda, ser determinada pelo respetivo grau de transparência fonológica e semântica. De acordo com Arnbak e Elbro (2000), a transparência diz respeito ao grau em que o som e o significado de uma palavra complexa são previsíveis a partir dos seus morfemas constituintes. Enquanto alguns morfemas têm relações fonologicamente transparentes, como feliz e felizmente, outros há que apresentam relações fonologicamente opacas, como razão e racional.

Apesar das mudanças fonológicas observadas na composição, derivação e flexão de um radical, este mantém, em muitos casos, a mesma ortografia nas diferentes palavras complexas de que faz parte (ibidem). Casos como dez e dezena ou sabor e saborear constituem exemplos de palavras em que o morfema radical se pronuncia diferentemente (/J/ vs. /z/ e /o/ vs. /u/, respetivamente) mas escreve-se do mesmo modo. Por esta razão, o conhecimento das relações morfológicas entre as palavras poderá ajudar a leitura e a escrita das mesmas, muitas vezes consideradas irregulares do ponto de vista das correspondências entre grafemas e fonemas.

Este conhecimento das estruturas e relações morfológicas das palavras, a par de habilidades para refletir sobre as mesmas e as manipular, constitui a essência da consciência morfológica (Carlisle, 2003). Como nos diz Apel (2014), trata-se de uma habilidade que encerra quatro dimensões: a consciência da forma falada e escrita dos morfemas, o significado dos afixos e respetivas alterações no significado e na classe gramatical do radical, o tipo de conexão entre os afixos escritos e o radical e sua alteração e, por fim, a relação entre o radical e as suas formas flexionadas e derivadas.

Atendendo à sua natureza, esta habilidade deixa antever um potencial contributo para o sucesso do ato de ler. De facto, vários têm sido os estudos que têm destacado a influência positiva que esta habilidade metalinguística exerce a nível da descodificação e da compreensão leitora (e.g., Apel, Brimo, Diehm, \& Apel, 2013; Arnbak \& Elbro, 2000; Casalis \& Colé, 2009; Kirby et al., 2012; Manolitsis, 2017). Também as revisões de literatura nesta área têm globalmente demonstrado a eficácia do treino a nível da consciência morfológica no desenvolvimento da literacia (e.g., Carlisle, 2010; Rueda-Sánchez \& López-Bastida, 2016). Tais resultados, no seu conjunto, reforçam a importância da criança possuir, quando da sua entrada para a escola, habilidades de consciência morfológica bem desenvolvidas. O meio onde esta se encontra inserida e o tipo de estimulação a que vai sendo exposta vão assumir um papel determinante neste desenvolvimento, já que a linguagem resulta da interação entre as capacidades inatas e os condicionantes ambientais. A família e a escola assumem-se, deste modo, como espaços de aprendizagens estruturantes e decisivos para $o$ desenvolvimento das crianças, constituindo-se como fatores explicativos das diferenças de desempenho observadas durante a escolarização (Mount-Cors, 2016). Importa, pois, dar continuidade aos estudos que procuram conhecer melhor o impacto do meio no desenvolvimento linguístico das crianças, com vista à identificação e caracterização das faltas de oportunidades e experiências existentes em alguns contextos e, em sentido inverso, dos ambientes e interações considerados mais ricos e estimulantes. Neste quadro, foi conduzido o presente estudo, que tem como finalidades avaliar o nível de desenvolvimento da consciência morfológica em crianças portuguesas de idade pré-escolar e caracterizar o papel do meio rural e urbano nesse desenvolvimento.

\section{Método}

\section{Participantes}

Participaram neste estudo 60 crianças, de ambos os sexos, com idades compreendidas entre os 4 e os 5 anos (cf. Tabela 1). Destas, metade encontrava-se a frequentar infantários em meio rural e a outra metade em meio urbano, ambos localizados na região Norte de Portugal.

Tabela 1.

Caracterização dos participantes

\begin{tabular}{lcccc}
\hline \multirow{2}{*}{ Grupo } & \multicolumn{2}{c}{ Sexo } & & Idade \\
\cline { 2 - 3 } \cline { 5 - 6 } & Fem. & Masc. & & Média (DP) \\
\hline Rural $(n=30)$ & 13 & 17 & & $5.02(0.18)$ \\
Urbano $(n=30)$ & 15 & 15 & & $4.95(0.29)$ \\
\hline
\end{tabular}

Todas as crianças encontravam-se a frequentar o último ano do pré-escolar, não tendo iniciado formalmente a aprendizagem da linguagem escrita. De acordo com a indicação do educador, nenhuma das crianças apresentava dificuldades de linguagem, de fala ou outros problemas. Todas tinham como língua materna o português e eram maioritariamente provenientes de um nível sócio-económico alto e médio alto (informação obtida a partir da escolaridade e profissão dos pais, segundo Norma, S.A.R.L., s.d.). 


\section{Material}

A avaliação da consciência morfológica foi efetuada a partir de tarefas construídas especificamente para o efeito (num total de 16), tendo em consideração as seguintes três variáveis: tipo de atividade (fluência, identificação, categorização, segmentação e apagamento), unidade de análise (morfema radical, morfema derivacional) e condição (palavra, pseudopalavra). A opção pela inclusão de pseudopalavras em todas as tarefas consideradas (com exceção da fluência) procurou assegurar que o desempenho da criança não era influenciado por fatores semânticos. Nas tarefas com palavras, e sempre que adequado, foram apresentadas imagens em simultâneo, de modo a reduzir eventual sobrecarga no sistema mnésico. Todas as tarefas foram precedidas por um item-treino, no sentido de garantir a compreensão, por parte da criança, do que era pedido. Os estímulos foram selecionados a partir da base lexical Porlex (Gomes \& Castro, 2003), controlando-se variáveis psicolinguísticas como a frequência, a extensão silábica e fonémica e o padrão fonológico.

Tarefas de fluência. Consistem em pedir à criança que, durante um tempo máximo de 2 minutos, evoque o maior número de palavras que contenham um determinado segmento. Este segmento pode ser um morfema radical (e.g., PORTA) ou um morfema derivacional (e.g., _MENTE). Ambas as tarefas de fluência compreendem um total de dois estímulos, correspondendo a pontuação final à média de palavras diferentes produzidas em cada uma das tarefas, sem inclusão de nomes próprios ou palavras flexionadas.

Tarefas de identificação. São tarefas de emparelhamento em que é pedido à criança que escolha, de entre 2 ou 3 estímulos, aquele que partilha um determinado radical ou afixo com uma dada palavra. $\mathrm{Na}$ prova de morfema radical em palavras (e.g., MOSQUITO), para além da palavra-alvo (MOSCA), é apresentado um distrator semântico (ABELHA) e um distrator fonológico (MAPA). Na prova de morfema derivacional em palavras (e.g., PORTÃO), para além da palavra-alvo (CALDEIRÃO) é apresentado um distrator que corresponde a uma palavra com terminação igual à palavra inicial mas sem constituir um morfema preso (MÃO). Cada resposta correta é cotada com 1 valor (0 para respostas incorretas), perfazendo um total máximo de 4 pontos em cada tarefa/unidade/condição.

Tarefas de categorização. Inspiradas na tarefa clássica de Bradley e Bryant (1983) de deteção de rima e de aliteração, é pedido à criança que encontre, de entre 4 estímulos, aquele que difere dos restantes por não partilhar o mesmo morfema radical (e.g., PINCEL vs. PINTOR - PINTAR - PINTURA) ou derivacional (e.g., AVENTAL vs. DEDAL - QUINTAL - POMBAL). Em cada uma das condições foram apresentados 4 conjuntos de 4 estímulos cada um, exceto no caso das tarefas de categorização de morfema em pseudopalavras, que, por razão da extensão dos estímulos (maioritariamente trissilábicos) e eventual efeito de sobrecarga no sistema mnésico, os conjuntos tinham apenas 3 estímulos. A cada resposta correta foi atribuída uma pontuação de 1 valor
(0 para respostas incorretas), perfazendo um total máximo de 4 pontos em cada tarefa/unidade/condição.

Tarefas de segmentação. Aqui é solicitada a divisão de palavras e de pseudopalavras (4 por condição) em unidades com significado, i.e., em morfema radical e sufixo derivacional (e.g., PORTÃO = PORTA + ÃO). A cada resposta correta foi atribuída uma pontuação de 1 valor (0 para respostas incorretas), perfazendo um total máximo de 4 pontos em cada tarefa/condição.

Tarefas de apagamento. Nestas tarefas, também designadas de subtração, é pedido à criança que diga como uma sequência de sons (palavras ou pseudopalavras) fica quando se retira um determinado morfema radical (e.g., TRISTEZA sem TRISTE) ou derivacional (e.g., DESCOSER sem DES_). Cada tarefa/unidade/condição contém 4 estímulos, sendo atribuído 1 valor por cada resposta correta, o que perfaz uma pontuação máxima de 4 pontos.

\section{Procedimento}

A avaliação da consciência morfológica foi realizada individualmente, num ambiente tranquilo. A ordem de administração das tarefas foi igual para todas as crianças, tendo-se iniciado pelas tarefas de fluência, seguidas das de identificação, categorização, segmentação e, por último, de apagamento. Em cada uma das tarefas, e sempre que aplicável, foram administradas primeiro as atividades que incidiam nos morfemas radicais em palavras e em pseudopalavras e só depois as relativas aos morfemas derivacionais (também primeiro as palavras e depois as pseudopalavras).

\section{Resultados}

Tendo em consideração a dimensão da amostra, procedeu-se à verificação da normalidade, através do teste de aderência de Kolmogorov-Smirnov com correcção de Lilliefors. O nível de significância obtido foi de .05 , indicando a ausência de distribuição normal para as variáveis dependentes consideradas no presente estudo. Assim, optou-se pela realização do teste nãoparamétrico de Mann-Whitney $U$ para análise de eventuais diferenças entre os grupos (Meio Urbano vs. Meio Rural) para cada uma das variáveis em análise.

Globalmente, as crianças do meio urbano apresentaram resultados acima da média para todas as medidas morfológicas consideradas enquanto as do meio rural se situaram sempre abaixo da média (cf. Figura 1). Este desvio em relação à média foi particularmente acentuado nas tarefas de categorização e de identificação de morfema derivacional em pseudopalavras; já nas restantes tarefas, a magnitude das diferenças intergrupais não foi tão evidente, tendo sido a identificação de morfema derivacional em palavras aquela em que os desempenhos mais se aproximaram da média.

De facto, quando se considera o efeito do Grupo, as diferenças significativas observaram-se apenas nas tarefas que melhor diferenciam as crianças do meio urbano das do rural, isto é, a nível da categorização de morfema radical em palavras e em pseudopalavras $(U=$ 248.500, $p=.002$ e $U=146.500, p \leq .001$, respetivamente), da categorização de morfema derivacional em palavras e em pseudopalavras $(U=$ 
$167.500, p \leq .001 \mathrm{e} U=89.500, p \leq .001$, respetivamente) e da identificação de morfema derivacional em pseudopalavras $(U=268.500, p=.005)$.

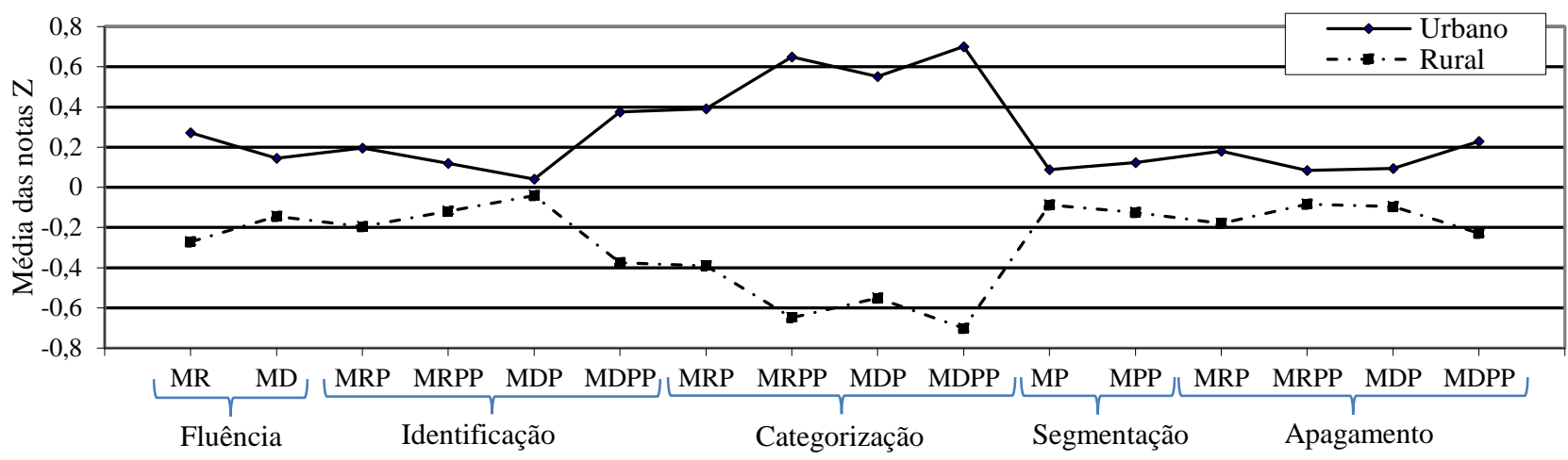

Figura 1. Total de acertos por grupo para cada tarefa de consciência morfológica $(\mathrm{M}=\mathrm{Morfema} ; \mathrm{R}=\mathrm{Radical}$; $\mathrm{D}=$ Derivacional; $\mathrm{P}=$ Palavras; $\mathrm{PP}=$ Pseudopalavras)

Nenhuma outra tarefa de identificação morfológica (identificação de morfema radical: $U=346.000, n s$, em palavras e $U=398.000$, $n s$, em pseudopalavras; identificação de morfema derivacional em palavras: $U=$ 412.500, $n s)$, assim como nenhuma tarefa de fluência (morfema radical: $U=336.000, n s ;$ morfema derivacional: $U=430.000, n s)$, de segmentação (palavras: $U=418.000, n s$; pseudopalavras: $U=380.000$, $n s$ ) e de apagamento (morfema radical: $U=354.000, n s$, em palavras, e $U=398.500, n s$, em pseudopalavras; morfema derivacional: $U=426.500, n s$, em palavras e $U$
$=334.000, \quad n s, \quad$ em pseudopalavras) atingiram significância.

Para uma melhor compreensão do sentido e da magnitude das diferenças significativas encontradas, apresenta-se, na Tabela 2, a estatística descrita por grupo e por tarefa. Um aspeto interessante que importa ressaltar prende-se com o baixo desempenho das crianças em todas as tarefas morfológicas, em particular a nível da fluência e da segmentação de morfemas (em que a maioria destas não consegue responder acertadamente a qualquer estímulo).

Tabela 2 .

Estatística descritiva por grupo e por tarefa de consciência morfológica ( $n=4$ nas tarefas de identificação, categorização e apagamento e $n=8$ nas tarefas de segmentação)

\begin{tabular}{|c|c|c|c|c|c|c|c|}
\hline \multicolumn{2}{|r|}{ Tarefa } & \multicolumn{3}{|c|}{ Urbano $(n=30)$} & \multicolumn{3}{|c|}{ Rural $(n=30)$} \\
\hline Tipo & Condição / Unidade ${ }^{1}$ & $\mathrm{M}(\mathrm{DP})$ & Med. & Min-Máx & $\mathrm{M}(\mathrm{DP})$ & Med. & Min-Máx \\
\hline \multirow[t]{2}{*}{ Fluência } & Morfema radical & $1.03(1.00)$ & 1.00 & $0-3$ & $0.55(0.69)$ & 0.00 & $0-2$ \\
\hline & Morfema derivacional & $0.47(0.86)$ & 0.00 & $0-3$ & $0.24(0.44)$ & 0.00 & $0-1$ \\
\hline \multirow[t]{4}{*}{ Identificação } & Morfema radical palavra & $2.57(1.01)$ & 3.00 & $0-4$ & $2.17(1.04)$ & 2.00 & $0-4$ \\
\hline & Morf. radical pseudopalavra & $3.07(0.83)$ & 3.00 & $1-4$ & $2.86(0.88)$ & 3.00 & $0-4$ \\
\hline & Morf. derivacional palavra & $2.07(1.39)$ & 2.50 & $0-4$ & $1.93(1.07)$ & 2.00 & $0-4$ \\
\hline & Morf. derivacional pseudopal. & $2.23(1.01)^{*}$ & 2.00 & $1-4$ & $1.41(1.09)^{*}$ & 2.00 & $0-4$ \\
\hline \multirow[t]{4}{*}{ Categorização } & Morfema radical palavra & $2.10(1.21)^{*}$ & 2.00 & $0-4$ & $1.14(1.16)^{*}$ & 1.00 & $0-4$ \\
\hline & Morf. radical pseudopalavra & $2.83(1.32)^{* *}$ & 3.00 & $0-4$ & $\begin{array}{c}0.80 \\
(1.06)^{* *}\end{array}$ & 0.00 & $0-3$ \\
\hline & Morf. derivacional palavra & $1.37(1.10)^{* *}$ & 1.00 & $0-4$ & $0.21(0.62)^{* *}$ & 0.00 & $0-3$ \\
\hline & Morf. derivacional pseudopal. & $2.43(0.90)^{* *}$ & 3.00 & $0-4$ & $0.62(0.98)^{* *}$ & 0.00 & $0-4$ \\
\hline \multirow[t]{2}{*}{ Segmentação } & Morfema palavra & $0.57(1.01)$ & 0.00 & $0-3$ & $0.41(0.91)$ & 0.00 & $0-3$ \\
\hline & Morfema pseudopalavras & $0.40(0.86)$ & 0.00 & $0-3$ & $0.21(0.77)$ & 0.00 & $0-3$ \\
\hline \multirow[t]{4}{*}{ Apagamento } & Morfema radical palavra & $2.57(1.22)$ & 3.00 & $0-4$ & $2.14(1.19)$ & 2.00 & $0-4$ \\
\hline & Morf. radical pseudopalavra & $2.87(1.07)$ & 3.00 & $0-4$ & $2.69(0.93)$ & 3.00 & $0-4$ \\
\hline & Morf. derivacional palavra & $2.37(1.07)$ & 2.00 & $1-4$ & $2.14(1.06)$ & 2.00 & $0-4$ \\
\hline & Morf. derivacional pseudopal. & $2.80(1.13)$ & 3.00 & $1-4$ & $2.17(1.23)$ & 2.00 & $0-4$ \\
\hline
\end{tabular}

Nota. $* p<.05 ; * * p<.001$

\section{Discussão}

Os resultados observados evidenciam um reduzido nível de desenvolvimento da consciência morfológica das crianças do estudo, independentemente do meio em que se encontram inseridas. Mesmo pertencentes a um nível sócio-económico alto e médio alto, o seu desempenho foi bastante baixo na maioria das tarefas, em particular a nível da fluência e da segmentação de morfemas, o que poderá resultar do facto de a capacidade de análise e de manipulação dos morfemas se desenvolver a partir da habilidade de reflexão sobre os sons da fala. Na verdade, se nos detivermos, a título ilustrativo, nas tarefas de fluência, verifica-se que as respostas dadas tendem a respeitar a fonologia do afixo mas não a sua natureza morfológica (e.g., dizer intervalo 
para o prefixo IN_ou semente para o sufixo _MENTE), sugerindo um processamento ainda muito centrado em segmentos sonoros. Se considerarmos que o processamento morfológico é mediado pelo processamento fonológico, tal resultado parece corroborar a hipótese de que a consciência morfológica é um construto que se desenvolve mais tardiamente, depois de as habilidades fonológicas se encontrarem relativamente consolidadas (Casalis \& Colé, 2009). Este desenvolvimento mais tardio poderá também estar relacionado com o facto de os Educadores estarem muito mais familiarizados com os conceitos de fonemas e de consciência fonológica, do que com os conceitos de morfemas e de consciência morfológica (Carlisle, 2003), daí que possivelmente estimulem mais a primeira, subvalorizando as atividades que promovam a aquisição da segunda.

O baixo desempenho nas tarefas de consciência morfológica foi particularmente evidente nos morfemas derivacionais em comparação com os morfemas radicais. Tal resultado está concordante com a literatura que refere que a morfologia derivacional se desenvolve mais lenta e tardiamente sendo os maiores ganhos observados durante a idade escolar (Casalis \& Louis-Alexandre, 2000).

Quando se considera o meio, verifica-se um melhor desempenho das crianças do meio urbano quando comparadas com as do meio rural. No entanto, esta diferença entre os grupos apenas foi significativa na tarefa de identificação de morfemas derivacionais em pseudopalavras e nas tarefas de categorização. Tal facto poderá encontrar explicação na natureza da atividade proposta. As tarefas de identificação e de categorização são tarefas implícitas e recetivas, sendo, por conseguinte, mais simples do que as tarefas de fluência (que apesar de implícitas têm uma natureza produtiva) e do que as de segmentação e de apagamento (que são explícitas e produtivas), na medida em que requerem apenas $o$ reconhecimento de morfemas ao invés da respetiva geração ou manipulação intencional (ibidem). Ora, o não desenvolvimento pleno destas duas últimas habilidades nestas idades, poderá esbater ou anular o efeito do meio, que a existir, tenderá a manifestar-se em idade escolar.

No seu conjunto, estes resultados, ainda que não permitam a sua generalização dadas as limitações do estudo (em termos da dimensão e características da amostra, das medidas utilizadas e das áreas avaliadas), apontam para a necessidade de se estimular precocemente a consciência morfológica em crianças dos meios rural e urbano, dotando-as de conhecimentos, capacidades e competências relevantes para a aprendizagem da leitura e da escrita. Como diz Carlisle (2010), a aquisição e o desenvolvimento da consciência morfológica por parte das crianças de idade pré-escolar é possível desde que se observe um ensino intencional da mesma. Neste quadro, os jardins de infância constituem locais privilegiados de desenvolvimento da sensibilidade morfológica, proporcionando atividades que incidam não só nas rimas, nas sílabas e nos fonemas mas também a nível dos morfemas. Este treino combinado da consciência morfológica com a consciência fonológica permitirá obter ganhos mais amplos nos níveis de literacia das crianças pequenas (Manolitsis, 2017). A adoção destas medidas neste contexto educativo, a par de um fortalecimento do suporte familiar nesta matéria, certamente permitirão melhorar o processo escolar das crianças e, na senda de Mount-Cors (2016), contribuir para minimizar, ou até eliminar, o fosso existente a nível da literacia entre o meio rural e o meio urbano.

\section{Referências}

Apel, K. (2014). A comprehensive definition of morphological awareness implications for assessment. Top Language Disorders, 34 (3), 197-209.

Apel, K., Brimo, D., Diehm, E., \& Apel, L. (2013). Morphological awareness intervention with kindergartners and first- and second-grade students from low socioeconomic status homes: A feasibility study. Language, Speech, and Hearing in Services at Schools, 44 (2), 161-173. doi: 10.1044/01611461(2012/12-0042)

Arnbak, E., \& Elbro, C. (2000). The effects of morphological awareness training on the reading and spelling skills of young dyslexics. Scandinavian Journal of Educational Research, 44 (3), 229-251.

Bradley, L. \& Bryant, P. E. (1983). Categorizing sounds and learning to read: A casual connection. Nature, 301, 419-421.

Carlisle, J. F. (2003). Morphology matters in learning to read: A commentary. Reading Psychology, 24, 291322.

Carlisle, J. F. (2010). Effects of instruction in morphological awareness on literacy achievement: An integrated review. Reading Research Quarterly, 45, 464-487.

Casalis, S., \& Colé, P. (2009). On the relationship between morphological and phonological awareness: Effects of training in kindergarten and in first-grade reading. First Language, 29, 113-142. doi:10.1177/0142723708097484

Casalis, S. \& Louis-Alexandre, M.-F. (2000). Morphological analysis, phonological analysis and learning to read French: A longitudinal study. Reading and Writing: An Interdisciplinary Journal, 12, 303335.

Gomes, I., \& Castro, S. L. (2003). Porlex, a lexical database in European Portuguese. Psychologica, 32, 91-108.

Kirby, L. R., Deacon, S. H., Bowers, P. N., Izenberg, L., Wade-Woolley, L., \& Parrila, R. (2012). Children's morphological awareness and reading ability. Reading and Writing: An Interdisciplinary Journal, 25, 389410.

Lieber, R. (2016). Introducing morphology ( $2^{\mathrm{a}}$ ed.). Cambridge: Cambridge University Press.

Manolitsis, G. (2017). How effective is morphological awareness instruction on early literacy skills?. In C. McLachlan, \& A. Arrow (Eds), Literacy in the early years. International perspectives on early childhood education and development (vol. 17). Singapore: Spring. doi: 10.1007/978-981-10-2075-9_9

Mount-Cors, M. F. (2016). Global literacy in local learning contexts. Connecting home and school. New York: Routledge. 
Rueda-Sánchez, M. I., \& López-Bastida, P. (2016). Efectos de la intervención en conciencia morfológica sobre la lectura, escritura y comprensión: Metaanálisis. Anales de Psicología, 31(1), 60-71. http://dx.doi.org/10.6018/analesps.32.1.196261

Villalva, A. (2009). Morfologia do português. Lisboa: Universidade Aberta. 